\title{
A APLICABILIDADE DA COMUNICAÇÃO NA PSICOLOGIA
}

\author{
Leiria, $\mathbf{M}$. \\ Aluna do 3ำano de Psicologia da Universidade Autónoma de Lisboa \\ marianaleiria99@gmail.com \\ Correia, I \\ Aluna do $3^{\circ}$ ano de Psicologia da Universidade Autónoma de Lisboa \\ Pinto, M. \\ Aluna do $3^{\circ} a n o$ de Psicologia da Universidade Autónoma de Lisboa \\ Galvão, S \\ Aluna do 3ํano de Psicologia da Universidade Autónoma de Lisboa \\ Lapa Esteves, M. \\ Docente da Universidade Autónoma de Lisboa (UAL). Portugal. \\ mlesteves@autonoma.pt
}

Recepción Artículo: 10 febrero 2020

Admisión Evaluación: 4 marzo 2020

Informe Evaluador 1: 13 marzo

Informe Evaluador 2: 17 marzo 2020

Aprobación Publicación: 20 abril 2020

\section{RESUMO}

Este trabalho tem como objetivo explicar como a comunicação afeta o indivíduo, quer a nível organizacional, quer a nível clínico. Começamos assim por definir quais os aspetos inerentes à comunicação, os diferentes tipos de comunicação e como estes têm diferentes resultados nas relações sociais. De seguida, explicamos o quão importante é a comunicação e o tipo de comunicação adequado no ambiente organizacional e no clínico, demonstrando uma situação especifica de burnout, cuja falha de comunicação atrapalhou e prejudicou a vida de indivíduos, no contexto organizacional; e ainda como a comunicação, ou a comunicação assertiva mais especificamente, tem impacto nas relações conjugais. Torna-se assim urgente a tomada de consciência de que devemo-nos abrir para A COMUNICAÇÃO.

Palavras-chave: comunicação; assertividade; organizacional; clínica; burnout

\section{ABSTRACT}

The applicability of communication in psychology. This article aims to explain how communication affects the individual, both organizationally and clinically. We begin by defining what are the inherent aspects of communication, the different types of communication, and how they have different outcomes in social relationships. Then we explain the importance of communication and the right type of communication in the organizational and clinical environment, demonstrating a specific burnout situation where communication failure has disrupted and damaged people's lives in the organizational context and also how communication, or assertive communica- 


\section{A APLICABILIDADE DA COMUNICAÇÃO NA PSICOLOGIA}

tion, has an impact on marital relations. This makes it urgent to become aware that we must open ourselves to COMMUNICATION.

Keywords: communication; assertiveness; organizational; clinic; burnout

\section{INTRODUÇÃO}

A comunicação tem um papel importantíssimo no desenvolvimento intelectual dos seres. De acordo com Braga (2001), os humanos são seres sociáveis, logo tem a necessidade de comunicar, a de desenvolver e melhorar técnicas comunicacionais, considerada importante no processo das relações humanas, uma vez que este passa maior parte do tempo a comunicar ou a interagir com os outros.

Existem cada vez mais métodos de comunicação, uma vez que embora esteja tudo praticamente confinado em aparelhos como o telemóvel ou o computador, cada aplicação instalada nos mesmos, terá a sua especificidade e permitir-nos-á comunicar com outras pessoas de diferentes maneiras.

No entanto, este trabalho tem como objetivo mostrar como um psicólogo pode comunicar de forma saudável e intervir de modo a ensinar outros a fazer o mesmo, para que as suas vidas melhorem, na medida em que serão mais felizes, tornar-se-ão pessoas mais motivadas a fazer diversas tarefas, e poderão ser pessoas mais produtivas.

\section{DESENVOLVIMENTO}

Comecemos por abordar a empatia, poia a empatia é extremamente importante na comunicação. Estudos revelaram que pessoas mais bem-sucedidas tinham um maior crescimento nas suas habilidades. Estas pessoas aprendem a ser mais empáticas observando outros (Goleman, 2001).

Como sabemos, a empatia é a capacidade psicológica de sentir aquilo que a outra pessoa sente, passar (na nossa mente) pelo mesmo que o outro está a passar, ou seja, colocarmo-nos no lugar do outro. A empatia é também uma capacidade de ajudar e de tentar compreender os sentimentos e emoções do outro individuo, experimentando de forma racional e objetiva o que a outra pessoa sente.

A empatia apresenta vários significados idênticos de acordo com vários autores. "A empatia envolve um sentimento de sensibilização pelas mudanças sentidas e refletidas, momento a momento, pela outra pessoa" (Rogers, 1992, citado em Costa \& Azevedo, 2010). "A empatia é um processo psicológico conduzido por mecanismos afetivos, cognitivos e comportamentais frente à observação da experiência do outro." (Davis, 1994, citado em Costa \& Azevedo, 2010).

Empatia em alemão significa Einfühlung e consiste em duas partes: "Ein = em" e "fühlen = sentir". A empatia é regularmente tratada como sinônimo de simpatia, o que, fenomenologicamente, é uma vivência psíquica, uma reação de ânimo (Ales Bello, 2004, citado em Ranieri \& Barreira, 2012). Empatizar é aceitar 00 outro como alter ego, como outro eu. Este é, segundo Manganaro (2002, citado em Ranieri \& Barreira, 2012), o ponto central da essência da empatia: "0 colhimento do 'tu' como alter ego".

As relações dialógicas acontecem a partir dos diálogos que estabelecemos com os outros. A presença do outro na nossa vida é essencial para a nossa aprendizagem acerca de nós mesmos e sobre as coisas do mundo.

"Falar é uma necessidade, escutar é uma arte" - Johann Goethe

A escuta ativa é uma técnica de comunicação que implica que, durante um diálogo ou processo de comunicação, o recetor comece por interpretar e compreender a mensagem que 0 emissor the transmite. Parece claro que quem ouve deva estar a prestar atenção ao que Ihe é dito, mas nem sempre isso é verdade, pois boa parte da informação que é transmitida pode ser mal interpretada ou pode nem ser ouvida com atenção pelo ouvinte. É muito frequentemente isto acontecer devido à falta de atenção por parte do ouvinte, stress ou outras variáveis razões.

Na escuta ativa, para além de ser necessário escutar com atenção 0 emissor, é também fundamental prestar atenção aos gestos e emoções demonstrados pelo emissor, durante todo o processo de comunicação, para que o recetor consiga compreender e interpretar a mensagem que lhe é transmitida, pois ouvir não é escutar. 
Aprender a escutar é essencialmente importante para desenvolver uma comunicação adequada levando a uma comunicação eficaz. Não sermos escutados ou sermos mal interpretados pode levar à ocorrência de muitos conflitos na nossa vida, tanto pessoais como profissionais.

Para uma boa comunicação, ou uma comunicação assertiva, é fundamental a capacidade de escutar e de se colocar no lugar do outro, pois mostra respeito e permite uma troca de informações eficazes.

\section{Comunicação Assertiva}

A comunicação assertiva é uma competência que pode ser aprendida e treinada que se define como a expressão de sentimentos, opiniões, desejos, ideias e preferências confortável e objetivamente, sem desrespeitar os direitos dos outros. (Kubany, Richard, Bauer \& Muraoka, 1992; Grilo, 2012).

Podemos identificar 7 atitudes pertencentes a uma personalidade assertiva:

- Atitude básica: exprime os seus direitos, diretamente;

- Atitude empática: exprime os seus direitos, mostrando empatia;

- Atitude discrepante: faz a distinção do que foi combinado do que está a ocorrer no momento;

- Expressão de sentimentos negativos: exprime quando e como 0 comportamento de outro 0 afeta;

- Atitude consequente: exprime os efeitos do comportamento do outro se este não o mudar e dá-lhe oportunidade para o fazer;

- Esclarecimento: determina os direitos do outro.

(Ferreira \& Esteves, 2010)

Uma comunicação não assertiva pode ser passiva ou agressiva. A personalidade passiva está presente na pessoa que não expressa os seus sentimentos, opiniões, desejos, ideias ou preferências, não respeitando os seus próprios direitos e, assim, dando a permissão de outros fazerem o mesmo (Galassi \& Galassi, 1977). As respostas passivas incluem hesitações, evitamento de certos assuntos, sentimento de ansiedade, repetidos pedidos de desculpa e expressões autodepreciativas, de modo a agradar outros e evitar ao máximo conflitos. Este tipo de comunicação pode dever-se ao medo das consequências negativas da expressão direta da sua opinião, à confusão entre assertividade e agressividade e ainda a crenças de desvalorização pessoal (Grilo, 2012).

A comunicação agressiva consiste na expressão de sentimentos, opiniões, desejos, ideias e preferências de forma hostil, insultuosa ou ameaçadora, desvalorizando os direitos de outros. (Galassi \& Galassi, 1977). As respostas agressivas podem incluir falar alto, interromper outros, utilizar excessivamente o "eu", expressões de ostentação, expressão de opiniões como se fossem factos, pedidos em forma de ordem, falar sarcasticamente, acusar e culpar outros (Grilo, 2012). Estas respostas podem ser originadas de crenças de superioridade, de insegurança e medo (Grilo, 2012). 


\section{A APLICABILIDADE DA COMUNICAÇÃO NA PSICOLOGIA}

Quadro 1 - Os três tipos de comunicação (adaptado de Grilo, 2012).

\begin{tabular}{|c|c|c|c|}
\hline & PASSIVO & AGRESSIVO & ASSERTIVO \\
\hline $\begin{array}{l}\text { Características do } \\
\text { comportamento }\end{array}$ & $\begin{array}{l}\text { Não expressa } \\
\text { desejos, ideias, } \\
\text { sentimentos ou } \\
\text { opiniões ou fá-lo de } \\
\text { forma auto- } \\
\text { depreciativa. } \\
\text { Objetivo: agradar }\end{array}$ & $\begin{array}{l}\text { Expressa desejos, } \\
\text { ideias, sentimentos } \\
\text { ou opiniões à custa } \\
\text { dos outros. } \\
\text { Objetivo: dominar } \\
\text { ou humilhar }\end{array}$ & $\begin{array}{l}\text { Expressa desejos, } \\
\text { ideias, sentimentos } \\
\text { ou opiniões de } \\
\text { forma direta e } \\
\text { apropriada. } \\
\\
\\
\text { Obejtivo: } \\
\text { comunicar }\end{array}$ \\
\hline $\begin{array}{l}\text { Sentimentos } \\
\text { próprio }\end{array}$ & $\begin{array}{l}\begin{array}{l}\text { Ansioso, } \\
\text { desapontado } \\
\text { consigo mesmo. }\end{array} \\
\text { Frequentemente } \\
\text { revoltado e } \\
\text { amargurado após o } \\
\text { seu } \\
\text { comportamento. }\end{array}$ & $\begin{array}{l}\text { Convencido da sua } \\
\text { superioridade. } \\
\text { Por vezes, } \\
\text { envergonhado após } \\
\text { o seu } \\
\text { comportamento. }\end{array}$ & $\begin{array}{l}\text { Confiante, } \\
\text { sentimentos } \\
\text { positivos sobre si } \\
\text { próprio, quer } \\
\text { durante, quer após o } \\
\text { seu } \\
\text { comportamento. }\end{array}$ \\
\hline $\begin{array}{l}\text { Sentimentos do } \\
\text { interlocutor }\end{array}$ & $\begin{array}{l}\text { Irritação, pena, } \\
\text { desagrado. }\end{array}$ & $\begin{array}{l}\text { Revolta, desejo de } \\
\text { vingança. }\end{array}$ & Respeito. \\
\hline Efeito & $\begin{array}{l}\text { Não alcança os seus } \\
\text { objetivos. } \\
\text { Aumento } \\
\text { revolta. }\end{array}$ & $\begin{array}{l}\text { Alcança os seus } \\
\text { objetivos, } \\
\text { magoando outros. }\end{array}$ & $\begin{array}{l}\text { Frequentemente } \\
\text { alcança os seus } \\
\text { objetivos. }\end{array}$ \\
\hline Resultado final & $\begin{array}{l}\text { Evitamento de } \\
\text { situações } \\
\text { desagradáveis, } \\
\text { evitamento de } \\
\text { conflitos, tensão e } \\
\text { confronto. }\end{array}$ & $\begin{array}{ll}\text { Descarga } & \text { de } \\
\text { revolta, } & \\
\text { sentimentos } & \text { de } \\
\text { superioridade. } & \end{array}$ & $\begin{array}{l}\text { Sentimentos } \\
\text { positivos, respeito } \\
\text { dos outros. } \\
\text { Aumento de auto- } \\
\text { confiança. } \\
\text { Promoção dos } \\
\text { relacionamentos. }\end{array}$ \\
\hline
\end{tabular}


A assertividade é "a ação direta, firme, positiva - e, quando necessário, persistente - que promove a equidade nas relações pessoais. A assertividade permite agir tendo em vista os melhores interesses do próprio, defender-se sem ansiedade excessiva, exercer os direitos pessoais sem negar os direitos dos outros, e expressar honesta e confortavelmente os próprios sentimentos." (Alberti \& Emmons, 2008, p.8). A comunicação assertiva inclui assim escutar os outros e elaborar questões para conhecer os pensamentos e sentimentos dos outros (Grilo, 2012).

\section{Comunicação na Psicologia Organizacional}

Ellionor e Gerard (1998) afirmar que 0 diálogo é uma prática fundamental de comunicação e de liderança capaz de transformar as pessoas e até a cultura organizacional. Deste modo, é importante que pessoas numa posição mais elevada na hierarquia das empresas/organizações valorizem a comunicação.

De acordo com João Ribeiro (2008), a comunicação nas organizações é importante para um bom desempenho da empresa e dos próprios trabalhadores. Estudos mostram que uma boa comunicação influencia a motivação dos trabalhadores, fazendo com que estes se sintam envolvidos, comprometidos e empenhados para desempenhar com qualidade as suas funções (Devesa, 2016). Uma boa comunicação dentro de uma empresa é capaz de resolver e prevenir conflitos, aumentando a satisfação e as relações com os outros que, por sua vez, aumenta a produtividade (Devesa, 2016).

A habilidade da comunicação é uma característica fundamental no mercado atual. Cada vez mais as empresas estão a investir em treinos para desenvolver uma comunicação assertiva. Uma pessoa não assertiva é prejudicial para os negócios pois podem ocorrer falhas na comunicação, dando origem a uma queda na produtividade, causando problemas no relacionamento entre colegas de trabalho e clientes, pois a sua comunicação pode gerar ressentimento e hostilidade (Devesa, 2016).

A comunicação assertiva é útil na resolução rápida de problemas, relacionamento interpessoal entre todos, aumento da motivação, cria um ambiente em que todos possam expressar suas ideias e reduz os problemas da equipa (Devesa, 2016).

Se a comunicação for pouco assertiva ou difusa podem ocorrer problemas, sendo assim importante que as organizações invistam na comunicação. A falta de transparência por parte de uma empresa é prejudicial e esta só se consegue evitar se houver uma boa comunicação interna.

\section{Notícia}

Existem alguns casos mediáticos de domínio publico, em que é clara a falha de comunicação. É muito importante ter em conta que a comunicação em contexto de trabalho, ou a falta dela, pode trazer graves consequências. Principalmente, nas grandes empresas, climas de instabilidade, grande pressão e falta de comunicação podem destabilizar o estado psicológico de um trabalhador.

Um desses casos, que na realidade é mais do que um caso, é o da France Telecom (atualmente Orange $\mathrm{S}$. A.), uma empresa que abrangia mais de 102,000 trabalhadores e onde começou a registar-se uma onda de suicídios a partir de 2008 até 2011 . A polémica que este caso apresentou deveu-se aos motivos apresentados pelos próprios trabalhadores em cartas de suicídio ou relatadas a familiares, amigos e colegas, pois estavam relacionados com o trabalho e 0 ambiente instável que se vivia na empresa. Apresentando alguns dados estatísticos e comparando a população francesa total e a população da empresa: em 102,000 trabalhadores da France Telecom, a percentagem de suicídios é de 15,3\% por ano, sendo que em 100,000 franceses a percentagem de suicídios é de 14,7\% por ano. No total, em cerca de 4 anos (2008 até 2011) foram registados 65 suicídios de trabalhadores desta entidade, sendo que, para além das cartas de suicídio deixadas a familiares, amigos e colegas, alguns destes trabalhadores puseram fim à sua vida no próprio local de trabalho: "A ultima vítima, uma advogada, atirou-se da janela do seu escritório, após ter enviado uma carta de suicídio ao seu pai via email" (Corkindale, 2009).

No entanto, este ambiente pouco saudável poderia ter sio revertido ou até mesmo evitado. Por exemplo, a aplicação da psicologia positiva, segundo um número crescente de pesquisas, está correlacionada com 0 


\section{A APLICABILIDADE DA COMUNICAÇÃO NA PSICOLOGIA}

ambiente de trabalho e os resultados que a empresa apresenta (Harter, Keyes e cols, 2003). Logo, se a população da empresa está "doente", o potencial dos trabalhadores não será com certeza explorado ao máximo e, por consequência, o lucro da empresa não é o melhor possível. Sendo assim, depreendemos que uma comunicação em que os discursos derrotistas e de culpabilização terão um efeito negativo e não altearão as empresas, mas também o país onde estão sediadas ao nível de desenvolvimento pretendido.

\section{Burnout}

0 trabalho tem grande valor na vida dos humanos, pois investimos grande parte na elaboração e no empenho no trabalho, ocupando maior parte da nossa vida. No entanto, o trabalho nem sempre proporciona um bom crescimento, reconhecimento e independência profissional, pois podem causar problemas de desagrado, desinteresse, irritação e extenuação (Pereira, 2002).

Burnout, em português, significa "perder o fogo", "perder a energia" ou "queimar para fora", muitos autores denominam o burnout de stress ocupacional (Codo \& Vasques-Menezes, 1999).

Foi Fregenbauer (1974, citado em Pereira, 2002) quem aplicou o termo Burnout no sentido que usamos hoje. 0 mesmo considera que, a partir de uma perspetiva clínica, o burnout representa um estado de exaustão devido ao trabalho exaustivo, deixando de lado as suas próprias necessidades.

0 burnout refere-se àquilo que deixou de trabalhar por completa falta de energia (França, 1987, citado em Carlotto, 2002), sucede-se quando o trabalhador perde a ligação que possui com o seu trabalho, começando a deixar de se importar com tudo e a achar que tudo o que faz é inútil não valendo a pena sequer continuar a fazêIo, ou seja, o trabalhador deixa de perceber o sentido da sua relação com o seu trabalho. A síndrome Burnout é definida por Maslach e Jackson (1981, citado em Carlotto, 2002) como "uma reação à tensão emocional crônica gerada a partir do contato direto e excessivo com outros seres humanos, particularmente quando estes estão preocupados ou com problemas. Cuidar exige tensão emocional constante, atenção perene; grandes responsabilidades espreitam o profissional a cada gesto no trabalho. 0 trabalhador se envolve afetivamente com os seus clientes, se desgasta e, num extremo, desiste, não aguenta mais, entra em Burnout."

Foram feitos variados estudos para identificar quais as causas do burnout. Farber (1991, citado em Carlotto, 2002) partia do pressuposto de que estas causas são uma combinação de fatores individuais, organizacionais e sociais, sendo que esta interação iria produzir uma perceção de baixa valorização profissional, tendo como resultado 0 burnout.

0 stress, a pressão, o mau ambiente no trabalho, a má relação com os colegas de trabalho assim como os problemas individuais, pode levar a exaustão emocional, surgindo assim o burnout.

A síndrome de burnout apresenta três dimensões:

- Exaustão emocional: quando os trabalhadores deixam de sentir energia, entusiamo e começam a sentir um esgotamento de recursos, ou seja, sentem que já não conseguem dar mais de si até a nível afetivo devido ao contato diário com os problemas.

- Despersonalização: quando o trabalhador começa a desenvolver sentimentos negativos e de cinismo ao público, principalmente usuários/clientes, ou seja, atribui a culpa do seu mal-estar às pessoas a quem se destina o seu trabalho.

- Falta de envolvimento pessoal no trabalho: quando o trabalhador começa a ter tendência a uma "evolução negativa" no trabalho, afetando as suas competências no trabalho e atendimento ou contacto com as pessoas usuárias do trabalho, assim como com a organização.

(Codo \& Vasques-Menezes, 1999)

\section{COMUNICAÇÃO NA PSICOLOGIA CLÍNICA}

0 trabalho do psicólogo reside nas relações interpessoais e, sendo que tem que criar uma relação de confiança e segura, a comunicação é essencial na mesma, assim como a forma como comunica.

Nesta comunicação é importante estarem presentes a escuta ativa, a atenção positiva incondicional, a com- 
preensão empática e treino assertivo (Ferreira \& Esteves, 2010; Gleitman, Fridlund \& Reisberg, 2014). Para tal, "0 apoio psicológico requer o desenvolvimento das capacidades empáticas e assertivas, estimulando o paciente a aumentar o seu nível de participação, ajudar a identificar as preocupações e problemas, incentivar a encontrar alternativas de resolução de problemas, e estabelecimento de uma relação terapêutica coesa." (Ferreira \& Esteves, 2010)

Ainda, o psicólogo tem que prestar atenção à linguagem não verbal do utente. Na falta de conforto em se expressar ou, em casos mais graves de psicopatologia, alguns utentes podem ter dificuldade em partilhar os seus pensamentos (Ferreira \& Esteves, 2010). Através de gestos, expressões faciais e corporais, e até do toque, ocorre uma transmissão de emoções e sentimentos.

A competência da comunicação assertiva permite ao psicólogo que se expresse de forma clara e ainda encoraje os seus clientes a fazer o mesmo de modo a ter conhecimento das suas necessidades e sentimentos (Grilo, 2012).

0 treino desta competência pela parte do utente vai permitir uma melhoria no seu comportamento e vida, em geral. Isto é, a comunicação assertiva está positivamente correlacionada com a autoestima, permitindo um maior controlo sobre a própria vida, maior satisfação nas suas relações interpessoais e alcançar objetivos desejados mais frequentemente (Nunes, 2008).

Tomemos como exemplo as relações conjugais de longa duração. Sendo o casamento uma realização importante na vida dos indivíduos (Féres-Carneiro, 1998), estes esperam o melhor, quer do próprio, quer do cônjuge (Wendling, 2007). Estudos mostram a importância da satisfação conjugal para a qualidade de vida do casal e para o bem-estar dos seus filhos (Mosmann, Wagner \& Féres-Carneiro, 2006) e, por vezes os problemas conjugais não estão no próprio conflito, mas sim na maneira como o casal resolve (Mosmann \& Falcke, 2011).

De acordo com Norgren et al. (2004), a durabilidade do casamento não significa que haja satisfação no casal. Existem fatores que mantêm a relação mesmo sem satisfação. Com o passar do tempo, os casais devem adaptar-se a novas situações e mudanças, ainda que muitos sintam dificuldade nesta tarefa.

As habilidades sociais têm um importante papel de prevenção e terapia na qualidade das relações (Del Prette, Villa, de Freitas \& Del Prette, 2008). Nestas habilidades sociais, estão incluídas a comunicação assertiva e a habilidade empática. As habilidades assertivas estão ligadas com comportamentos de manifestação de opinião, concordar/discordar, fazer, aceitar e recusar pedidos, construir relacionamento afetivo e sexual, expressar raiva, encerrar relações, entre outros. É importante que a relação seja de igual para igual. Um dos comportamentos mais assertivo é o gesto de desculpar-se (Del Prette \& Del Prette, 2001). Uma comunicação clara e assertiva evita mal interpretações. A empatia é outra habilidade importante pois evita conflitos e promove a satisfação no casal (Figueiredo, 2005). A empatia promove sentimentos de maior segurança e valorização nas relações.

\section{CONCLUSÃO}

Foi possível através deste trabalho percebermos quais a diferentes formas de comunicação (assertiva, passiva e agressiva), compreender de que forma o recetor recebe a informação e como se comporta apos receber a mesma.

É passível também poder-se tirar algumas conclusões deste trabalho sobre a aplicabilidade da comunicação, nomeadamente sobre a forma como o psicólogo pode utilização a mesma e a onde aplicar.

Pode-se compreender melhor como a comunicação ou a falta dela podem afetar o individuo, ou uma população, quer seja na esfera pessoal ou no contexto de trabalho, e quais as consequências para o próprio individuo, mas também para quem o rodeia.

\section{REFERÊNCIAS BIBLIOGRÁFICAS}

Alberti, R., \& Emmmons, M. (2008). Your perfect right ( $\left.g^{a} e d\right)$. California: Impact Publishers

Braga, L. (2001). Constituição do campo da comunicação. In Cohn, G. Et al, Campoda comunicação. João Pessoa: Ed. UFPB.

Cabe, C., \& Timmins, F. (2003). Teaching assertiveness to undergraduate nursing students. Nurse Education in Practice, 3, 30-42. 


\section{A APLICABILIDADE DA COMUNICAÇÃO NA PSICOLOGIA}

Carlotto, M. S. (2002). A síndrome de burnout e o trabalho docente. Psicologia em estudo, 7(1), 21-29.

Codo, W., \& Vasques-Menezes, I. (1999). 0 que é burnout. Educação: carinho e trabalho, 2, 237-254.

Corkindale, G. (2010). Why Are France Telecom Workers Comminttig Suicide?. In Harvard Business Review

Costa, F. D. D., \& Azevedo, R. C. S. D. (2010). Empatia, relação médico-paciente e formação em medicina: um olhar qualitativo. Revista Brasileira de Educação Médica.

Del Prette, Z. A., \& Del Prette, A. (1999). Psicologia das habilidades sociais: terapia e educação. Vozes.

Del Prette, Z. A. P., Villa, M. B., de Freitas, M. G., \& Del Prette, A. (2008). Estabilidade temporal do inventário de habilidades sociais conjugais (IHSC). Avaliação Psicológica, 7(1), 67-74.

DEJOURS, C. (1998). 0 sofrimento no trabalho-entrevista com Christophe Dejours por Catherine Combase, trad. Provisória de Ana Inês C. de Mello. Critique communiste, (158).

Devesa, L. M. (2016). A importância da comunicação no contexto organizacional.

Ellionor, Linda; Gerard, Glenna. Diálogo: redescobrindo o poder transformador da conversa. São Paulo: Futura, 1998.

Féres-Carneiro, T. (1998). Casamento contemporâneo: 0 difícil convívio da individualidade com a conjugalidade. Psicologia: reflexão e crítica, 11(2), 0.

Ferreira, J., \& Esteves, M. L. (2010). A PEÇA QUE FALTA: COMUNICAÇÃO. International Journal of Developmental and Educational Psychology, 4(1), 367-374.

Figueredo, P. D. M. V. (2005). A influência do lócus de controle conjugal, das habilidades sociais conjugais e da comunicação conjugal na satisfação com o casamento. Ciências \& Cognição, 6.

Gerschenfeld, A. (2010). Entrevista a Christophe Dejours: um suicídio no trabalho é uma mensagem brutal.

Gleitman, H., Fridlund, A. J. \& Reisberg, D. (2014). Psicologia (10ª ed.). Lisboa: Fundação Calouste Gulbenkian.

GOLEMAN, D. Trabalhando com a inteligência emocional. Rio de Janeiro: Objetiva, 2001.

Grilo, A. M. (2012). Relevância da assertividade na comunicação profissional de saúde-paciente. Psicologia, Saúde \& Doenças, 13(2), 283-297.

Kubany, E. S., Richard, D. C., Bauer, G. B., \& Muraoka, M. Y. (1992). Impact of assertive and accusatory communication of distress and anger: A verbal component analysis. Aggressive Behavior, 18(5), 337-347.

Letovsky, R. (2013). The workplace that kills: Suicides at france télécom. Georgetown Institute for the Study of Diplomacy.

Mosmann, C., \& Falcke, D. (2011). Conflitos conjugais: motivos e frequência. Revista da SPAGESP, 12(2), 5-16.

Mosmann, C., Wagner, A., \& Féres-Carneiro, T. (2006). Qualidade conjugal: mapeando conceitos. Paidéia, 16(35), 315-325.

Norgren, M. D. B. P., Souza, R. M. D., Kaslow, F., Hammerschmidt, H., \& Sharlin, S. A. (2004). Satisfação conjugal em casamentos de longa duração: uma construção possível. Estudos de Psicologia, 9(3), 575584.Nunes, P. (2008). Psicologia positiva.

PAZ, R. (2009). France Telecom: 24 suicídios em 18 meses. Sapo. Pt.

Pereira, A. M. T. B. (2002). Burnout: quando o trabalho ameaça o bem-estar do

trabalhador. Casa do Psicólogo.

Ranieri, L. P., \& Barreira, C. R. A. (2012). A empatia como vivência. Memorandum: Memória e História em Psicologia, 23, 12-31.

Ribeiro. J. (2008). Comportamento Organizacional. Acesso em 05/10/2016.

URL:http://tecempreende.anje.pt/system/files/items/344/original/ComportamentoOrgan-v11- final.pdf

Santos, C. (2013). A importância de uma escuta ativa (Doctoral dissertation).

Selli, M. S., Remião, J. A. A., \& Axt, M. (2011). A escuta como possibilidade de reflexão/construção de uma prática dialógica. Anais do XVI seminário internacional de educação, Cachoeira do Sul, 464-476.

Wendling, M. I. (2007). 0 casamento na contemporaneidade: Construindo espaços para 0 Eu e 0 Nós na relação. Pensando Famílias, Porto Alegre, 11(1), 87-105. 